\title{
OPTIMIZING THE THERMAL GRADIENT AND THE PULLING SPEED IN A THERMOPLASTIC PULTRUSION PROCESS OF PET/E GLASS FIBERS USING FINITE ELEMENT METHOD
}

\author{
Nataša Z. Tomićl ${ }^{*}$, Marija M. Vuksanović ${ }^{1}$, Bojan I. Međo', Marko P. Rakin ${ }^{2}$, \\ Dejan D. Trifunović, ${ }^{2}$ Dušica Stojanović ${ }^{2}$, Petar Uskoković ${ }^{2}$, \\ Radmila M. Jančić - Heinemann ${ }^{2}$, Vesna J. Radojević ${ }^{2}$ \\ ${ }^{1}$ Innovation center of Faculty of Technology and Metallurgy, \\ Karnegijeva 4, 11120 Belgrade, Serbia \\ ${ }^{2}$ University of Belgrade, Faculty of Technology and Metallurgy, \\ Karnegijeva 4, 11120 Belgrade, Serbia
}

Received 19.06.2018

Accepted 25.06.2018

\begin{abstract}
A thermoplastic pultrusion process was examined using commercial fiber roving of $\mathrm{PET} / \mathrm{E}$ glass, to determine the optimum pulling speed and optimal zonal temperatures. Finite element analysis predicted heat transfer through the commingled fibers and air in the pultrusion die. The cross-section of obtained rods was examined, and image analysis was carried out to obtain information about the degree of fiber impregnation, number of voids and uniformity of fiber distribution. Optimizing the temperature field for the pultrusion of poly (ethylene terephthalate) is of significant importance. The pulling speed has the same importance. These two parameters are closely related as evidenced by the analysis of images.
\end{abstract}

Keywords: poly (ethylene terephthalate) - PET; pultrusion; finite element method - FEM; image analysis.

\section{Introduction}

Pultrusion is a manufacturing process widely used for continuous production of fiber-reinforced composites [1]. In recent years, the pultrusion process experienced a remarkable growth within the composite industry, due to its cost-effectiveness, automation, and high quality of products. Nowadays, the process is widely used to manufacture wind turbine blades, window profiles, door panels, and reinforcing bars for concrete $[2,3]$. A lot of numerical simulations have been done in the last twenty years

* Corresponding author: Nataša Tomić,ntomic@tmf.bg.ac.rs 
because a practical set up of pultrusion process is not possible without a numerical analysis of the technological process [4].

Pultrusion of thermoplastic fibers combined with glass fibers gains importance due to the simplicity and absence of toxic polymerization products during production that occur in thermo-reactive polymers pultrusion. Products of thermoplastic pultrusion can be reshaped when reheated. The product obtained in this process can be recycled after use.

One of the main parameters in the pultrusion process is temperature regime controlled using the zonal temperatures. Until the optimal temperature ranges achieved, effects of low and high temperatures can be studied. Due to the high temperature in one zone PET degrades, crystallizes and changes color which causes a decrease in mechanical properties. If the temperature in a zone is low, PET will not be able to impregnate E-glass fiber fully. Another critical parameter is the pulling speed. Pulling speed determine the time of passing through pultrusion die. If the speed is higher than optimal, the fibers will not be able to be impregnated to the focal pultruded rod, and if it is lower that can lead to overheating of the pultruded rod. Pulling speed dictates the production volume in commercial production. In addition, it is of great importance to achieve the most significant possible pulling speed producing a quality product.

With the cross-section analyzing, it is possible to determine which model of impregnation is most represented in observed samples. There are two models: quadratic and hexagonal, where difference density of packaging is achieved. Model of packaging may suggest the efficiency of fiber impregnation [5]. Longitudinal section is closely related to the cross-section showing the void status in the composite [6]. Both sections can be examined using optical microscopy.

In a thermo-reactive pultrusion process pulling speed is mainly associated with the reaction speed [7]. Considering that there is no chemical reaction in a thermoplastic pultrusion process, impregnation of fibers is related only to the temperature of the polymer and the time that is available for the polymer to flow and impregnate glass fibers. This phenomenon is examined at centerline temperature.

A numerical procedure is developed in order to calculate the temperature field in the process. The model is capable of providing accurate and reliable parameters that can be used in the real process [8]. In this paper, heat transfer from the heater to the commingled fiber will be considered.

It is essential not to exceed degradation temperature for poly (ethylene terephthalate) which is at $270-285{ }^{\circ} \mathrm{C}$ when hydrolytic reactions are induced [9]. The melting temperature of PET is higher than $250{ }^{\circ} \mathrm{C}$, and preferably $260{ }^{\circ} \mathrm{C}$. So, the zone temperature must be between those temperatures. It can be slightly higher at the end to induce better heat transfer and to enable higher pulling speed. PET doesn't allow great temperature variations in pultrusion process because there is the thin boundary between melting and degradation temperature.

\section{Experiment}

Materials

The primary material used in this paper is TWINTEX® RPET70N184 (2690 tex) from Fiber Glass Industries, Inc., USA. It is a roving made of comingled E-glass and 
thermoplastic polyester (PET) filaments. This is ready to use the product, and it is used in the pultrusion process without any other preparation. Table 1 shows the mark meaning and the product specification.

Table 1. Product reference and mark meaning for TWINTEX® RPET70N184 (2690 tex).

\begin{tabular}{cc}
\hline Mark & Meaning \\
\hline $\mathrm{R}$ & Roving \\
PET & Polyester resin \\
70 & Glass content in weight $\%$ \\
$\mathrm{~N}$ & Natural color \\
184 & Yield in linear yards per pound (269tex) \\
\hline
\end{tabular}

Thermoplastic pultrusion process

PET is a thermoplastic resin that can be remelted and shaped without any chemical reaction. PET fibers are melting in a pultrusion die and impregnate the E-glass fiber. The better impregnation is achieved, the better mechanical properties of the composite are obtained. The pultrusion die has three temperature zones. Fiber mixture is heated by furnace whose temperature regime is formed depending on the type of thermoplastic polymers. For PET, the first zone is used to preheat the polymer, in the range of 523-533 $\mathrm{K}$, in the second zone to melt the polymer at the temperature of 533$543 \mathrm{~K}$, in the third zone to form the shape of the composite at a temperature of 533-548 $\mathrm{K}$. The fibers from the different sources of the windings are guided and pulled into the pultrusion die, Fig. 1a. Zone temperatures are being set on the digital panel and easy to follow, Fig. 1b.

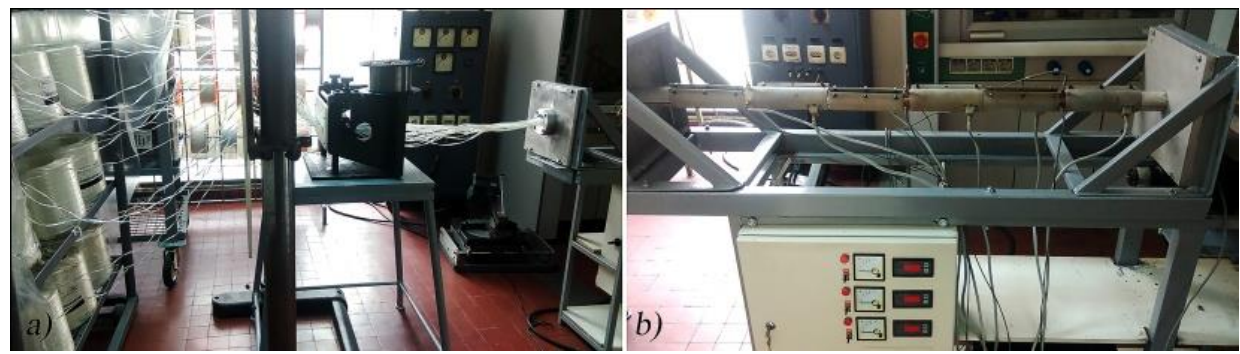

Fig. 1. a) Fiber from the windings on the stand guided to the pultrusion entrance, and b) the pultrusion zones.

It can be seen that every zone has its gauge that enables precise measurements of temperatures and a quick response to maintain the same. The line for thermoplastic pultrusion is a pilot plant machine serving in product development in Department of Special and Structural Materials of Faculty of Technology and Metallurgy, University of Belgrade. In this paper, the focus will be just on one part of the pultrusion process, and that is the pultrusion furnace, the temperature regime in it and the correlation of the pulling speed to the quality of the composite obtained. Three samples were tested for 
every set of processing parameters, and the representative ones are presented in the paper.

Image analysis for determining parameters resulting in the impregnation process

The software Image-Pro Plus 4.0, Media Cybernetics, allows measuring the degree of impregnation and determining the volume fraction of the glass fibers. The density of packaging and the type of fibers impregnation will be determined by crosssection examination [5]. Two different samples will be observed in order to determine efficiency in impregnation according to the temperature regime set and the pulling speed.

Finite element method in the thermoplastic pultrusion process

Finite element method (FEM) is a numerical method used to simulate the heat transfer in the pultrusion die. This method gives an insight into the temperatures of the composite in centerline and on the surface. Both of these temperatures are important to set the optimal parameters of the process. The temperature in centerline is an indicator of fibers heating performance. The temperature on the surface is controlled not to exceed the temperature of polymer degradation.

The three-dimensional model is developed consisting of steel pultrusion die and a mixture of fiber and air passing the die. The material properties passing the material die are lumped Twintex and air properties [7, 8, 10-12]. There is a considerable content of air in the middle of a die that must be considered [13]. Having in mind the diameters of pultrusion inlet $(\varnothing 15)$ and pultrusion nozzle $(\varnothing 8 \mathrm{~mm})$ calculated air content in pultrusion die 72 vol.\%. Material properties are presented in Table 2.

Table 2. Material properties used in the numerical simulation.

\begin{tabular}{|c|c|c|c|c|}
\hline Material & $\begin{array}{c}\text { Density, } \\
\rho \\
(\mathrm{kg} / \\
\left.\mathrm{m}^{3}\right)\end{array}$ & $\begin{array}{l}\text { Coefficient of linear } \\
\text { thermal expansion, } \alpha \\
\qquad(\mathrm{m} / \mathrm{mK})\end{array}$ & $\begin{array}{c}\text { Conductivity, } \\
\kappa(\mathrm{W} / \mathrm{mK})\end{array}$ & $\begin{array}{c}\text { Specific } \\
\text { heat, } \\
C_{\mathrm{p}} \\
(\mathrm{J} / \mathrm{kgK})\end{array}$ \\
\hline Twintex RPET & 1950 & $8 \mathrm{e}^{-06}$ & 0.900 & 1240 \\
\hline Air (on $523 \mathrm{~K}$ ) & 675 & - & 0.042 & 1034 \\
\hline Lumped $\left(\mathrm{V}_{\mathrm{f}}=78 \%\right)$ & 1032 & $8 \mathrm{e}^{-06}$ & 0.282 & 1092 \\
\hline Steel die & 7850 & $1.3 \mathrm{e}^{-05}$ & 40.00 & 460 \\
\hline
\end{tabular}

The coefficient of linear thermal expansion of air is not considered because the pultrusion die is not entirely closed, so the air pressure is being reduced to atmospheric pressure. Different pulling speeds are tested: $10,20,50$ and $100 \mathrm{~cm} / \mathrm{min}$, so as temperatures set: $\mathrm{T}_{1}=523 / 533 \mathrm{~K}, \mathrm{~T}_{2}=533 / 543 \mathrm{~K}$, and $\mathrm{T}_{3}=538 / 548 \mathrm{~K}$.

Both of parts are meshed using C3D8T finite elements in Abaqus 6.10. CAE- An 8 -node thermally coupled brick, trilinear displacement, and temperature elements. The interaction between the fibers and PET matrix was modeled as "Surface to surface" contact with finite sliding. There were three interactions according to the three temperature zones. Simulation is performed in a coupled temperature-displacement step. Seven boundary conditions are applied: the first and second are prescribed as an $\mathrm{X}$ (U1=UR2=UR3) and $\mathrm{Y}$ symmetry $(\mathrm{U} 2=\mathrm{UR} 1=\mathrm{UR} 3)$, and the third is encastre - a displacement /rotation limit $(\mathrm{U} 1=\mathrm{U} 2=\mathrm{U} 3=\mathrm{UR} 1=\mathrm{UR} 2=\mathrm{UR} 3=0)$ for the fixed lateral 
surface of the die. The fourth boundary condition is a velocity set in $\mathrm{m} / \mathrm{s}$ units. The following three boundary conditions are zone temperatures in a coupled temperaturedisplacement step. Predefined field is set for an ambient temperature of 293 K. Fig. 2 shows the assembly and mesh used in the numerical simulation. Length of the pultrusion die is $1.15 \mathrm{~m}$.

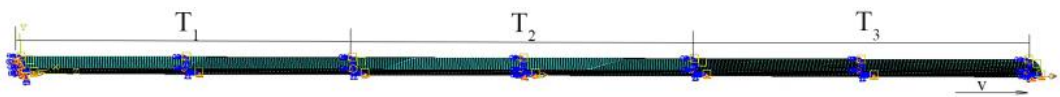

Fig. 2. Part assembly used in FEM.

\section{Results and discussion}

\section{Finite element model of thermoplastic pultrusion}

Three-dimensional finite element model gives as colorful insight into the heat transfer from the surface to the centerline of the composite. First tested temperature set is $\mathrm{T}_{1}=523 \mathrm{~K}, \mathrm{~T}_{2}=533 \mathrm{~K}, \mathrm{~T}_{3}=538 \mathrm{~K}$ with three pulling speeds: $v_{1}=10 \mathrm{~cm} / \mathrm{min}, \mathrm{v}_{2}=25$ $\mathrm{cm} / \mathrm{min}, v_{3}=50 \mathrm{~cm} / \mathrm{min}$, and $v_{4}=100 \mathrm{~cm} / \mathrm{min}$. For another analysis pulling speeds remain the same but zone temperatures were increased by $10{ }^{\circ} \mathrm{C}$. In the first test, full melting of PET is achieved at speeds 10 and $25 \mathrm{~cm} / \mathrm{min}$, Fig. 3 a, b. For pulling speed of $50 \mathrm{~cm} / \mathrm{min}$, one part of the center composite is not fully melted where the impregnation couldn't be completed, Fig. 3c. High-temperature gradient can be seen for pulling speed of $100 \mathrm{~cm} / \mathrm{min}$, which suggests that this speed cannot be a good choice.
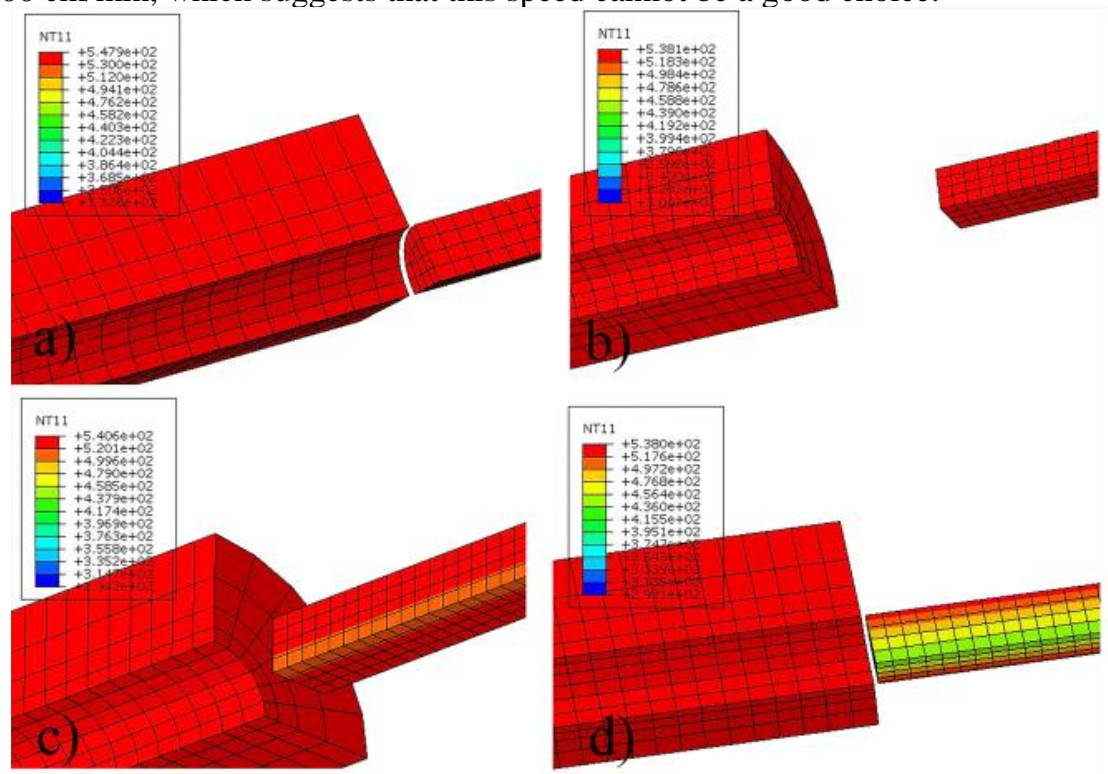

Fig. 3. Nodal temperature of the PET/E glass composite exiting the pultrusion die under temperature set $\left(T_{1}=523 \mathrm{~K}, T_{2}=533 \mathrm{~K}, T_{3}=538 \mathrm{~K}\right)$ with pulling speed: a) $10 \mathrm{~cm} / \mathrm{min}$, b) $25 \mathrm{~cm} / \mathrm{min}$, c) $50 \mathrm{~cm} / \mathrm{min}$, and d) $100 \mathrm{~cm} / \mathrm{min}$. 
To achieve higher production volume, there was an option to increase the speed of drawing and zonal temperature which has also been an option in numerical analysis Fig. 4. There is again a high thermal gradient for speed $100 \mathrm{~cm} / \mathrm{min}$. Another important issue that needs to be taken into consideration is that the surface temperature does not exceed the degradation temperature of PET.

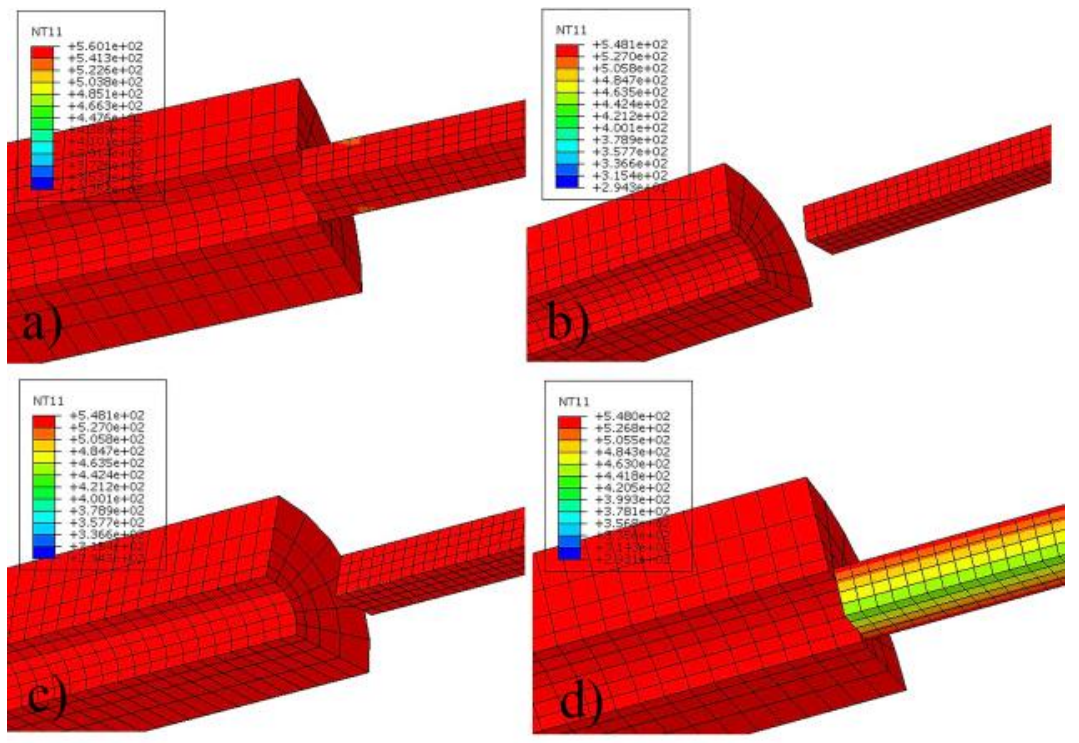

Fig. 4. Nodal temperature of the PET/E glass composite exiting the pultrusion die under temperature set $\left(T_{1}=533 \mathrm{~K}, T_{2}=543 \mathrm{~K}, T_{3}=548 \mathrm{~K}\right)$ with pulling speed: a) $10 \mathrm{~cm} / \mathrm{min}$, b) $25 \mathrm{~cm} / \mathrm{min}$, c) $50 \mathrm{~cm} / \mathrm{min}$, and d) $100 \mathrm{~cm} / \mathrm{min}$.

In order to have a better insight into the thermal state, the diagrams obtained in numerical analysis are taken into considerations.
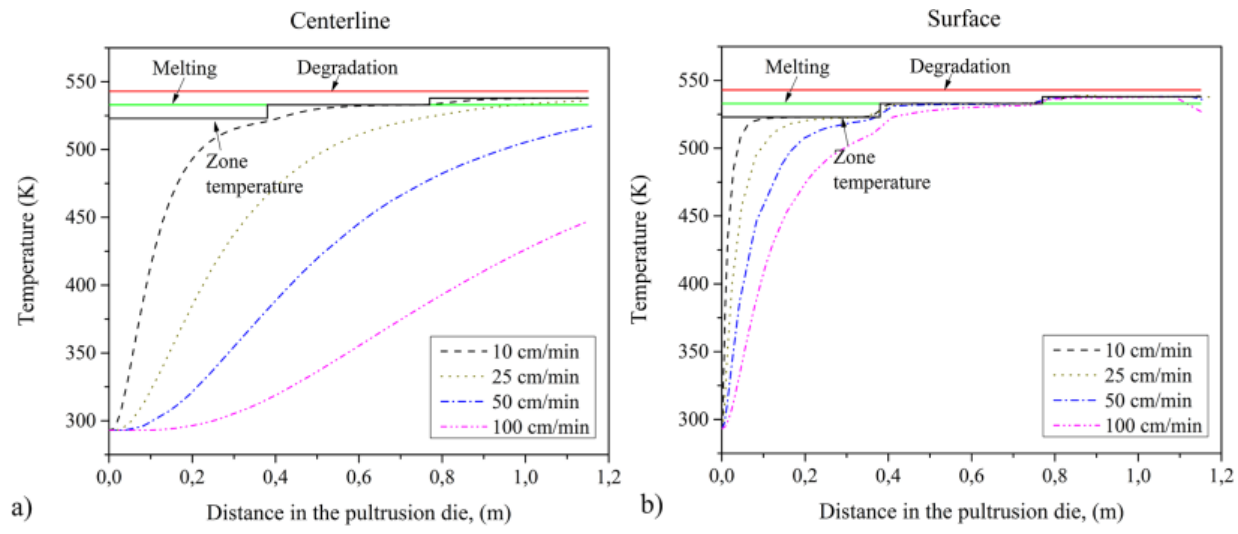

Fig. 5. The temperature of the composite: a) centerline and b) surface under temperatures $\left(T_{1}=523 \mathrm{~K}, T_{2}=533 \mathrm{~K}, T_{3}=538 \mathrm{~K}\right)$. 
The diagram shows that speed of 10 and $25 \mathrm{~cm} / \mathrm{min}$ achieved zone above melting and under degradation point, Fig. 5a. Speeds higher than $25 \mathrm{~cm} / \mathrm{min}$ significantly shift the graph down. It could be concluded that the surface of the composite quickly equalizes with zone temperatures on exit, Fig. 5 b.

Riskier is to increase speed and zone temperatures. In a case of increasing zone temperatures just in $10 \mathrm{~K}$, low speeds lead center of the composite to enter the degradation zone, Fig. 6a. The use of high speed (50 and $100 \mathrm{~cm} / \mathrm{min}$ ) ensures enough time to achieve the melting point.
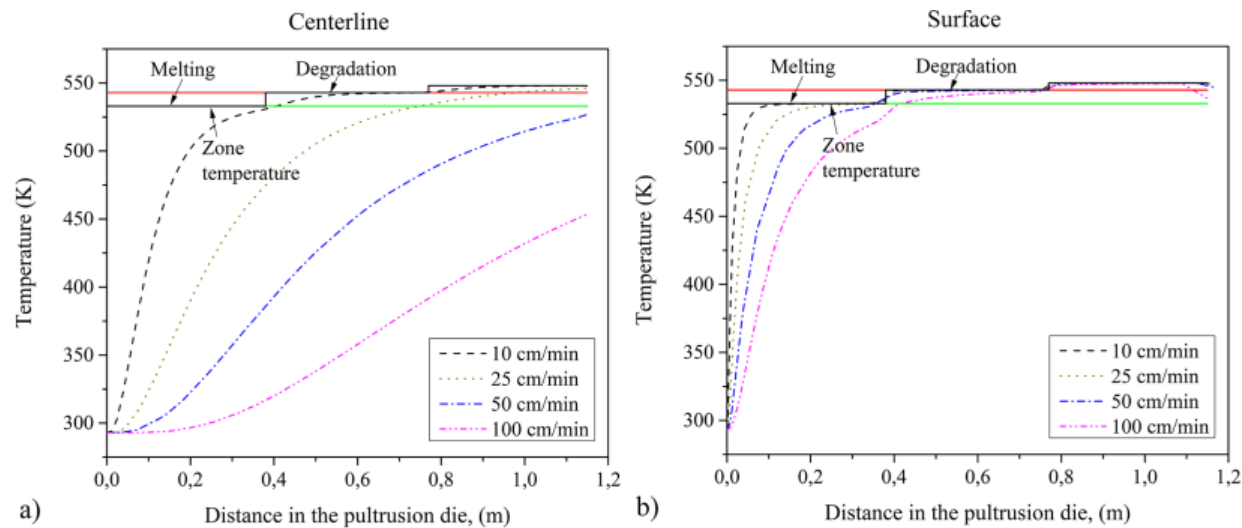

Fig. 6. The temperature of the composite: a) centerline and b) surface under temperatures set $\left(T_{1}=533 \mathrm{~K}, T_{2}=543 \mathrm{~K}, T_{3}=548 \mathrm{~K}\right)$.

Looking at the surface temperatures, all the speeds enter the degradation zone, Fig. 6b. So, an increase in the temperature leads to the problem of polymer degradation that must be avoided.

\section{Determining the impregnation degree}

Glass weight content of Twintex is $70 \%$, so the volume content is $55 \%$. This value will be referent value for determining the degree of impregnation and void content. The cross sections were captured on an optical microscope. Two samples were obtained on two different pulling speeds. According to the FEM analysis, Sample 1, produced at pulling speed of $25 \mathrm{~cm} / \mathrm{min}$, was determined like optimum speed to obtain full impregnation. Sample 2 is produced at pulling speed of $50 \mathrm{~cm} / \mathrm{min}$ and will be used for comparative purposes, Fig. 7. 

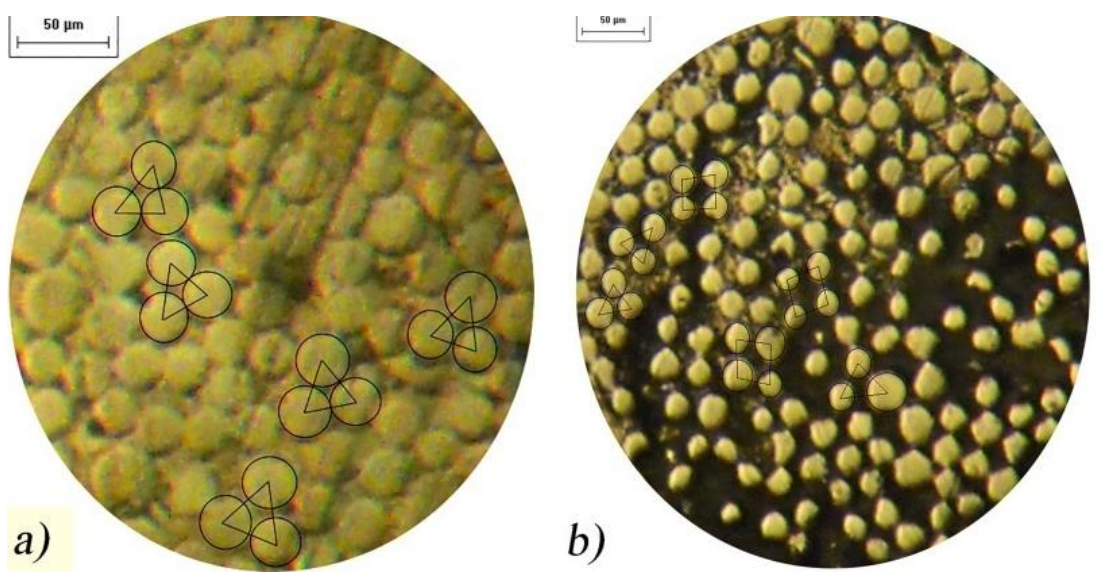

Fig. 7. Cross section of a) Sample 1 with complete impregnation of E glass with $P E T /\left(25 \mathrm{~cm} / \mathrm{min}, T_{1}=523 \mathrm{~K}, T_{2}=533 \mathrm{~K}\right.$ and $\left.T_{3}=538 \mathrm{~K}\right)$ and $\left.\mathrm{b}\right)$ Sample 2 with partly impregnation $\left(50 \mathrm{~cm} / \mathrm{min}, T_{1}=523 \mathrm{~K}, T_{2}=533 \mathrm{~K}\right.$ and $\left.T_{3}=538 \mathrm{~K}\right)$.

The pictures show clear differences in the type and degree of impregnation. Fig. $7 \mathrm{a}$ shows mostly the hexagonal type of impregnation, while Fig. $7 \mathrm{~b}$ shows mixed types of impregnation - hexagonal and quadratic. When the pultrusion process parameters are optimal, the polymer is wetting all the glass fibers making a homogenous composite with the dense packaging of fibers as can be seen in Fig. 7a. If the pulling speed is higher PET doesn't have enough time to melt and impregnate the glass fiber.

The differences can be also seen on longitudinal section. Fig. 8a is showing complete impregnation of glass fibers with PET along the entire section without visible voids (Sample 1). Fig. 8b suggests the existence of voids at the intersection of insufficiently heated composites (Sample 2) and the content is presented in Table 3.

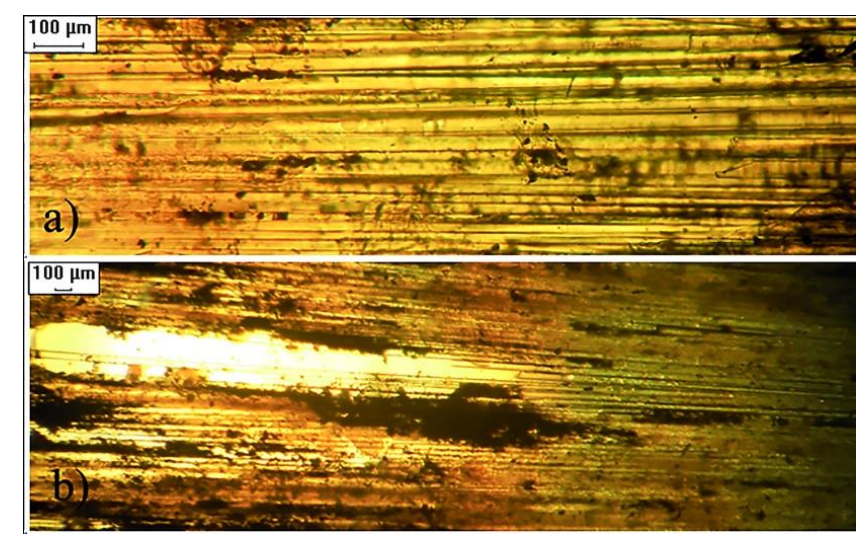

Fig. 8. Longitudinal section of PET/E glass composites: a) Sample 1 with complete impregnation of E glass with PET/ $\left(25 \mathrm{~cm} / \mathrm{min}, T_{1}=523 \mathrm{~K}, \mathrm{~T}_{2}=533 \mathrm{~K}\right.$ and $\left.T_{3}=538 \mathrm{~K}\right)$ and $b$ ) Sample 2 with partly impregnation $\left(50 \mathrm{~cm} / \mathrm{min}, T_{1}=523 \mathrm{~K}, \mathrm{~T}_{2}=533 \mathrm{~K}\right.$ and $T_{3}=538 \mathrm{~K}$ ). 
Analyzing the optical microscopy images, results describing the consequence of pultrusion parameters are obtained, Table 3. Analysis of Fig. 8a gives information about very dense packaging indicating a good set of parameters and good impregnation achieved.

Table 3. Image analysis results of the composite cross-section (Fig. 7).

\begin{tabular}{|c|c|c|c|c|}
\hline & $\begin{array}{c}\text { Type of } \\
\text { impregnation }\end{array}$ & $\begin{array}{l}\text { Packaging } \\
\text { density, \% }\end{array}$ & $\begin{array}{c}\text { Glass fiber } \\
\text { content, vol. } \\
\%\end{array}$ & $\begin{array}{c}\text { Void content, } \\
\text { vol. } \%\end{array}$ \\
\hline Sample 1 & Hexagonal & $67.10( \pm 1.27)$ & 54.82 & $\begin{array}{l}\text { no visible } \\
\text { voids }\end{array}$ \\
\hline Sample 2 & $\begin{array}{l}\text { Mixed hexagonal } \\
\text { and quadratic }\end{array}$ & $44.98( \pm 9.03)$ & 46.70 & 8.27 \\
\hline
\end{tabular}

In order to examine effects of pultrusion parameters, it was chosen to increase zone temperatures. When the temperature is higher than melting temperature and close to degradation temperature, the surface of the composite start to degrade and change color. The zone temperatures were increased just $10{ }^{\circ} \mathrm{C}$, the pulling speed was 25 $\mathrm{cm} / \mathrm{min}$, and the effect was more than evident.

\section{Conclusion}

Studies in this paper show that the developed 3D model closely simulates heat transfer and this procedure is stable, reliable and gives results comparable to experiments. Different models were developed to simulate temperature effect and effect of pulling speed to find optimum ratio of those two parameters. It was found that the optimum speed is $25 \mathrm{~cm} / \mathrm{min}$ and zone temperatures $\mathrm{T}_{1}=523 \mathrm{~K}, \mathrm{~T}_{2}=533 \mathrm{~K}, \mathrm{~T}_{3}=538 \mathrm{~K}$, and those parameters obtained from numerical analysis help us to obtain a sample with full impregnation without polymer degradation. This model can be used for other pultrusion materials, temperature ranges and pulling speed.

\section{Acknowledgments}

This research has been financed by the Ministry of Education, Science and Technological Development of the Republic of Serbia as a part of the project TR34011 and ON174004.

\section{References}

[1] S. Koubaa, S. L. Corre, C. Burtin: J Reinf Plast Comp, 32 (2013) 1285-1294.

[2] P. Carlone, I. Baran, J. H. Hattel, G.S. Palazzo: Adv Mech Eng, 301875 (2013) 114.

[3] P. Carlone, G.S. Palazzo, R. Pasquino: Comput Math Appl, 53 (2007) 1464-1471.

[4] P. Akishin, E. Barkanov, A. Bondarchuk: 2nd International Conference on Innovative Materials, Structures and Technologies, Riga, Latvia, 2015, 1-10.

[5] S. M. Haffner, K. Friedrich, P. J. Hogg, J. J. C. Busfield: Appl Compos Mater, 5 (1998) 237-255.

[6] C. J. Creighton, T. W. Clyne: Compos Sci Technol, 60 (2000) 525-533.

[7] I. Baran, C.C. Tutum, J. H. Hattel: Appl Compos Mater, 20 (2013) 639-653. 
[8] X. L. Liua, I. G. Crouchb, Y. C. Lam: Compos Sci Technol, 60 (2000) 857-864.

[9] F. Samperia, C. Puglisia, R. Alicatab, G. Montaudo: Polym Degrad Stabil, 83 (2004) 3-10

[10] I. Baran, C. C. Tutum, J. H. Hattel: Appl Compos Mater, 20 (2013)449-463.

[11] I. Baran, J. H. Hattel, C.C. Tutum: Appl Compos Mater, 20 (2013) 1247-1263.

[12] B. R. Suratno, L. Ye,Y. W. Mai: Compos Sci Technol, 58 (1998) 191-197.

[13] G. Bechtold, S. Wiedmer, K. Friedrich: J Thermoplast Compos, 15(2002) 443-465.

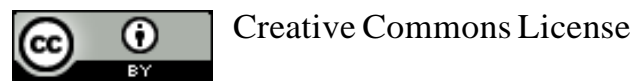

This work is licensed under a Creative Commons Attribution 4.0 International License. 